Research Article

\title{
On Best Proximity Point Theorems in Locally Convex Spaces Endowed with a Graph
}

\author{
B. Saadaoui $\mathbb{D D}^{1},{ }^{1}$. Lazaiz ${ }^{D},{ }^{2}$ and M. Aamri ${ }^{1}$ \\ ${ }^{1}$ Laboratory of Algebra, Analysis and Applications, Department of Mathematics, Ben M'sik Faculty of Sciences, \\ University of Hassan II, Casablanca, Morocco \\ ${ }^{2}$ LASMA Laboratory, Department of Mathematics, Dhar El Mahraz Faculty of Sciences, \\ University of Sidi Mohamed Ben Abdellah, Fes, Morocco \\ Correspondence should be addressed to B. Saadaoui; saadaoui.brahim2015@gmail.com
}

Received 20 April 2020; Accepted 30 June 2020; Published 1 August 2020

Academic Editor: Jean Michel Rakotoson

Copyright (c) 2020 B. Saadaoui et al. This is an open access article distributed under the Creative Commons Attribution License, which permits unrestricted use, distribution, and reproduction in any medium, provided the original work is properly cited.

\begin{abstract}
We consider the problem of best proximity point in locally convex spaces endowed with a weakly convex digraph. For that, we introduce the notions of nonself $G$-contraction and $G$-nonexpansive mappings, and we show that for each seminorm, we have a best proximity point. In addition, we conclude our work with a result showing the existence of best proximity point for every seminorm.
\end{abstract}

\section{Introduction}

Fixed point theorems deal with conditions under which maps (single or multivalued) have invariant points. The theory itself is a beautiful mixture of analysis (pure and applied), topology, and geometry. Over the last 50 years or so, the theory of fixed point has been revealed as a very powerful and important tool in the study of nonlinear phenomena. In particular, fixed point techniques have been applied in such diverse fields as biology, chemistry, economics, engineering, game theory, and physics. If the fixed point equation of given mapping does not have a solution, then it is of interest to find an approximate solution for the fixed point equation. In other words, we are searching for an element in the domain of the mapping, whose image is as close to it as possible. This situation motivates the researchers to develop the notion of best proximity point theory. It is worth to note that the best proximity point theorems can be viewed as a generalization of fixed point theorems, since most fixed point theorems can be derived as corollaries of best proximity point results (for more details, see $[1-6])$.

Fan in [7] gave a common generalization of both theorems of Kakutani and Tychonoff. He proved under compactness of the domain in a locally convex space that every upper semicontinuous set valued mapping has a fixed point in the sense that there is an element which belongs to his image.

In [8] Ling established some properties relating the concepts of normal structure and submeans in a Hausdorff locally convex space and obtained a fixed point theorem for left reversible semigroups of nonexpansive mapping with a compactness of the domain. This extends a result obtained by Lau and Takahashi in Banach space [9] (generalization of Lim's fixed point) and shows that Lau and Takahashi's result remains valid in the more general setting of a locally convex space.

Vuong in [10] established a fixed point theorem for nonexpansive mappings in a locally convex space with normal structure and the compactness of the domain.

In this paper, we define the concept of nonself $G$-contraction mappings in locally convex spaces endowed with a digraph $G$. Then, we obtain sufficient conditions for the existence of a best proximity point for such mappings when both the domain and the range satisfy the $P$-property condition. In addition, we discuss some existence results for nonself $G$-nonexpansive mappings. 


\section{Preliminaries}

To start this work, we discuss some of the basic notations and terminologies which we will be using later. Let $E$ be a Hausdorff locally convex space and $\mathscr{P}$ be a family of continuous seminorms which generates the topology of $E$. Let $A, B$ be two subsets of $E$ and $p \in \mathscr{P}$.

$$
\begin{aligned}
\delta_{p}(A) & =\sup \left\{p\left(x-x^{\prime}\right): x, x^{\prime} \in A\right\}, \\
\operatorname{dist}_{p}(A, B) & =\inf \{p(x-y): x \in A ; y \in B\} .
\end{aligned}
$$

Recall that a mapping $T: A \longrightarrow A$ is said to be contraction if there is $\alpha \in[0,1)$ for any $x, y \in A$ :

$$
p(T x-T y) \leq \alpha p(x-y)
$$

and $T: A \longrightarrow A$ is said to be nonexpansive if for any $x, y \in A$,

$$
p(T x-T y) \leq p(x-y) .
$$

Recall that a pair $(A, B)$ satisfies a property if both $A$ and $B$ has that property. For example, $(A, B) \subseteq(C, D) \Leftrightarrow A \subseteq C$ and $B \subseteq D$.

Let $(A, B)$ be a pair of sets in a Hausdorff locally convex space $(E, \mathscr{P})$. Define

$$
\begin{aligned}
& A_{0}^{p}=\left\{x \in A: p\left(x-y^{\prime}\right)=\operatorname{dist}_{p}(A, B) \text { for some } y^{\prime} \in B\right\}, \\
& B_{0}^{p}=\left\{y \in B: p\left(x^{\prime}-y\right)=\operatorname{dist}_{p}(A, B) \text { for some } x^{\prime} \in A\right\} .
\end{aligned}
$$

Clearly, we have

$$
\left(A_{0}^{p}, B_{0}^{p}\right) \subseteq(A, B) .
$$

A directed graph or digraph $G$ is determined by a nonempty set $V(G)$ of its vertices and the set $E(G) \subset V(G) \times V(G)$ of its directed edges. A digraph is reflexive if each vertex has a loop. For more details, one can consult the book [11].

Definition 1. Given a digraph $G=(V, E)$.

If whenever $(x, y) \in E(G) \Rightarrow(y, x) \notin E(G)$, then the digraph $G$ is called an oriented graph.

A digraph $G$ is transitive whenever $[(x, y) \in E(G)$ and $(y, z) \in E(G)] \Rightarrow(x, z) \in E(G)$, for any $x, y$, $z \in V(G)$.

A dipath of $G$ is a sequence $a_{0}, a_{1}, \ldots, a_{n}, \ldots$ with $\left(a_{i}, a_{i+1}\right) \in E(G)$ for each $i \in \mathbb{N}$.

A finite dipath of length $n$ from $x$ to $y$ is a sequence of $n+1$ vertices $\left(a_{0}, a_{1}, \ldots, a_{n}\right)$ with $\left(a_{i}, a_{i+1}\right) \in E(G)$ and $x=a_{0}, y=a_{n}$.

$[x]_{G}$ is the set of all vertices which are contained in some path beginning at $x$ (i.e., $y \in[x]_{G} \Leftrightarrow$ there exist $\left(a_{0}, a_{1}, \ldots, a_{n}\right)$ with $\left(a_{i}, a_{i+1}\right) \in E(G)$ and $x=$ $\left.a_{0}, y=a_{n}\right)$.

A digraph is weakly convex if and only if for any $x, y, z$, and $h$ in $E$,

$$
x \in[z]_{G}, y \in[h]_{G} \text {, and } \lambda \in[0,1] .
$$

We have

$$
\lambda x+(1-\lambda) y \in[\lambda z+(1-\lambda) h]_{G} .
$$

The letter $\widetilde{G}$ denotes the undirected graph obtained from $G$ by ignoring the direction of edges.

Let $(A, B)$ be a pair such that $A_{0}^{p}$ is nonempty.

Definition 2. Let $(E, \mathscr{P})$ be a locally convex space endowed with a digraph $G$ and $A, B \subset E$. A mapping $T: A \longrightarrow B$ is said to be $G$-contraction mapping if there exists $k \in[0,1)$, for any $x, y \in A$ such that $y \in[x]_{G}$ :

(a) $p(T x-T y) \leq k p(x-y)$.

(b) For any $x_{1}, x_{2} \in A_{0}^{p}$,

$$
\left\{\begin{array}{l}
p\left(x_{1}-T x\right)=\operatorname{dist}_{p}(A, B) \\
p\left(x_{2}-T y\right)=\operatorname{dist}_{p}(A, B)
\end{array} \Rightarrow x_{2} \in\left[x_{1}\right]_{G}\right.
$$

Definition 3. Let $(E, \mathscr{P})$ be a locally convex space endowed with a digraph $G$ and $A, B \subset E$. A mapping $T: A \longrightarrow B$ is said to be $G$-nonexpansive mapping if for any $x, y \in A$ such that $y \in[x]_{G}$ :

(a) $p(T x-T y) \leq p(x-y)$.

(b) For any $x_{1}, x_{2} \in A_{0}^{p}$,

$$
\left\{\begin{array}{l}
p\left(x_{1}-T x\right)=\operatorname{dist}_{p}(A, B) \\
p\left(x_{2}-T y\right)=\operatorname{dist}_{p}(A, B)
\end{array} \Rightarrow x_{2} \in\left[x_{1}\right]_{G}\right.
$$

Definition 4. Let $(A, B)$ be a pair of sets in a Hausdorff locally convex space $(E, \mathscr{P})$. Define $A_{0}^{p} \neq \varnothing$. Then, the pair $(A, B)$ is said to have the $P$-property if and only if

$$
\left\{\begin{array}{l}
p\left(x_{1}-y_{1}\right)=\operatorname{dist}_{p}(A, B) \\
p\left(x_{2}-y_{2}\right)=\operatorname{dist}_{p}(A, B)
\end{array} \Rightarrow p\left(x_{1}-x_{2}\right)=p\left(y_{1}-y_{2}\right)\right.
$$

for all $x_{1}, x_{2} \in A$ and $y_{1}, y_{2} \in B$.

Definition 5. We will say that a nonempty subset $A$ of $E$ is

(1) $[.]_{G}$-compact if and only if for every net $\left(x_{\alpha}\right)_{\alpha \in \Omega}$ in $A$ such that $x_{\alpha} \in\left[x_{\beta}\right]_{G}$, there is a subnet $\left(x_{\alpha_{1}}\right)_{\alpha_{1} \in \Omega}$ which is converging to a point $x \in A$ and $x \in\left[x_{\alpha^{\prime}}\right]_{G}$ for any $\alpha^{\prime} \in \Omega$.

(2) Sequentially [. $]_{G}$-compact if and only if for every sequence $\left(x_{n}\right)_{n \geq 1}$ in $A$ such that $x_{n+1} \in\left[x_{n}\right]_{G}$, there exists a subsequence $\left(x_{k_{n}}\right)_{k}$ of $\left(x_{n}\right)_{n \geq 1}$ which is converging to a point in $A$ and $x \in\left[x_{n}\right]_{G}$. 


\section{Main Results}

The proof of the next result follows the same pattern of ([12], Theorem 3.2). For the sake of completeness, we give the proof.

Theorem 1. Let $(E, \mathscr{P})$ be a locally convex space endowed with a reflexive digraph $G$. Let $(A, B)$ be a nonempty pair in $E$ such that $(A, B)$ has the P-property and $A$ is convex complete. Let $T: A \longrightarrow B$ be a G-contraction mapping such that $T\left(A_{0}^{p}\right) \subseteq B_{0}^{p}$. Assume that

(i) There exist $x_{0}$ and $x_{1}$ in $A_{0}^{p}$ such that $x_{1} \in\left[x_{0}\right]_{G} \subseteq A_{0}^{p}$ and $p\left(x_{1}-T x_{0}\right)=\operatorname{dist}_{p}(A, B)$.

(ii) For any sequence $\left(s_{n}\right)_{n \in \mathbb{N}}$ in $A$ with $s_{n} \longrightarrow s$ and $s_{n+1} \in\left[s_{n}\right]_{G}$ for any $n \in \mathbb{N}, s \in\left[s_{n}\right]_{G}$.

Then, there exist $x^{*} \in A_{0}^{p}$ such that $p\left(x^{*}-T x^{*}\right)=$ $\operatorname{dist}_{p}(A, B)$.

Proof. Let $p \in \mathscr{P}$. By (i), there exist two points $x_{0}, x_{1} \in A_{0}^{p}$ such that $x_{1} \in\left[x_{0}\right]_{G}$ and

$$
p\left(x_{1}-T x_{0}\right)=\operatorname{dist}_{p}(A, B),
$$

and a finite sequence $\left(y_{0}^{i}\right)_{i=0}^{i=N}$ of $A_{0}^{p}$ such that $x_{0}=y_{0}^{0}, y_{0}^{1}, \ldots, y_{0}^{N}=x_{1}$ and $y_{0}^{i} \in\left[y_{0}^{i-1}\right]_{G}$ for all $i \in\{1,2, \ldots, N\}$. that

As $y_{0}^{1} \in A_{0}^{p}$ and $T\left(A_{0}^{p}\right) \subseteq B_{0}$, there exist $y_{1}^{1} \in A_{0}^{p}$ such

$$
p\left(y_{1}^{1}-T y_{0}^{1}\right)=\operatorname{dist}_{p}(A, B),
$$

and since $p\left(x_{1}-T x_{0}\right)=\operatorname{dist}_{p}(A, B)$ and $y_{0}^{1} \in\left[x_{0}\right]_{G}$, by the condition (b) of Definition 2, we get

$$
y_{1}^{1} \in\left[x_{1}\right]_{G}
$$
that

Similarly, for $i=2,3, \ldots, N$, there exist $y_{1}^{i} \in A_{0}^{p}$ such

$$
\begin{aligned}
p\left(y_{1}^{i}-T y_{0}^{i}\right) & =\operatorname{dist}_{p}(A, B), \\
y_{1}^{i} & \in\left[y_{1}^{i-1}\right]_{G},
\end{aligned}
$$

for all $1 \leq i \leq N+1$.

Now, let $x_{2}=y_{1}^{N}$. Thus, the finite sequence $\left(y_{1}^{i}\right)_{i=0}^{i=N}$ is a path from $x_{1}=y_{0}^{N}=y_{1}^{0}$ to $y_{1}^{N}=x_{2}$.

Again, since $y_{1}^{i} \in A_{0}^{p}$ and $T\left(A_{0}^{p}\right) \subseteq B_{0}^{p}$ for each $i=0,1,2, \ldots, N$, there exist $y_{2}^{i} \in A_{0}^{p}$ such that

$$
\begin{aligned}
p\left(y_{2}^{i}-T y_{1}^{i}\right) & =\operatorname{dist}_{p}(A, B), \\
y_{2}^{i} & \in\left[y_{2}^{i-1}\right]_{G},
\end{aligned}
$$

for all $i \in\{1, \ldots, N+1\}$. Also, we have

$$
\begin{gathered}
p\left(x_{2}-T x_{1}\right)=\operatorname{dist}_{p}(A, B), \\
x_{2} \in\left[x_{1}\right]_{G} .
\end{gathered}
$$

Continuing in this manner for all $n \in \mathbb{N}$, we obtain a sequence $\left(x_{n}\right)_{n \in \mathbb{N}}$ where

$$
\begin{aligned}
x_{n+1} & \in\left[x_{n}\right]_{G}, \\
p\left(x_{n+1}-T x_{n}\right) & =\operatorname{dist}_{p}(A, B) .
\end{aligned}
$$

Produce a path $\left(y_{n}^{i}\right)_{i=0}^{i=N}$ from $x_{n}=y_{n}^{0}$ to $y_{n}^{N}=x_{n+1}$ (see Figure 1 for illustration) in such a way that

$$
p\left(y_{n}^{i+1}-T y_{n}^{i}\right)=\operatorname{dist}_{p}(A, B), \quad \forall i=0,1, \ldots, N-1 .
$$

Using the $P$-property of $(A, B)$ and equation (18) for any $n \in \mathbb{N}$, we have

$$
p\left(y_{n}^{i-1}-y_{n}^{i}\right)=p\left(T y_{n-1}^{i-1}-T y_{n-1}^{i}\right), \quad \forall i=1, \ldots, N+1 .
$$

Now, for each $n \in \mathbb{N}$,

$$
\begin{aligned}
p\left(x_{n}-x_{n+1}\right) \leq & p\left(y_{n}^{0}-y_{n}^{N}\right) \leq p\left(y_{n}^{0}-y_{n}^{1}\right) \\
& +p\left(y_{n}^{1}-y_{n}^{2}\right)+p\left(y_{n}^{2}-y_{n}^{3}\right)+\ldots \\
& +p\left(y_{n}^{N-1}-y_{n}^{N}\right)=\sum_{i=1}^{N+1} p\left(y_{n}^{i-1}-y_{n}^{i}\right) \\
= & \sum_{i=1}^{N+1} p\left(T y_{n-1}^{i-1}-T y_{n-1}^{i}\right) .
\end{aligned}
$$

Since for all $n \in \mathbb{N}$ and $1 \leq i \leq N+1, y_{n}^{i} \in\left[y_{n}^{i-1}\right]_{G}$ and $T$ is a $G$-contraction, it follows that for any $n \in \mathbb{N}$,

$$
p\left(x_{n}-x_{n+1}\right) \leq \alpha \sum_{i=1}^{N+1} p\left(y_{n-1}^{i-1}-y_{n-1}^{i}\right),
$$

for some $\alpha \in[0,1)$. Repeating the process, it follows that for all $n \in \mathbb{N}$,

$$
p\left(x_{n}-x_{n+1}\right) \leq M \alpha^{n},
$$

where $M=\sum_{i=1}^{N+1} p\left(y_{0}^{i}-y_{0}^{i-1}\right)$. Hence, $\left(x_{n}\right)_{n}$ is a Cauchy sequence. So, $x_{n} \longrightarrow x^{*} \in A$. By condition (ii), we get $x^{*} \in\left[x_{n}\right]_{G}$ for any $n \in \mathbb{N}$. Hence,

$$
p\left(T x_{n}-T x^{*}\right) \leq \alpha p\left(x_{n}-x^{*}\right),
$$

i.e.,

$$
p\left(T x_{n}-T x^{*}\right) \longrightarrow 0,
$$

where by continuity of $p$, we get

$$
p\left(x_{n+1}-T x_{n}\right) \longrightarrow p\left(x^{*}-T x^{*}\right) .
$$

Since $p\left(x_{n+1}-T x_{n}\right)=\operatorname{dist}_{p}(A, B)$, we obtain

$$
p\left(x^{*}-T x^{*}\right)=\operatorname{dist}_{p}(A, B) \text {. }
$$

Theorem 2. Let $(E, \mathscr{P})$ be a locally convex space endowed with a weakly convex and reflexive digraph $G$. Let $(A, B)$ be a nonempty pair that has the P-property in E. Let T: $A \longrightarrow B$ be a $G$-nonexpansive mapping such that $A$ is convex complete and $T\left(A_{0}^{p}\right) \subseteq B_{0}^{p}$. Assume that 


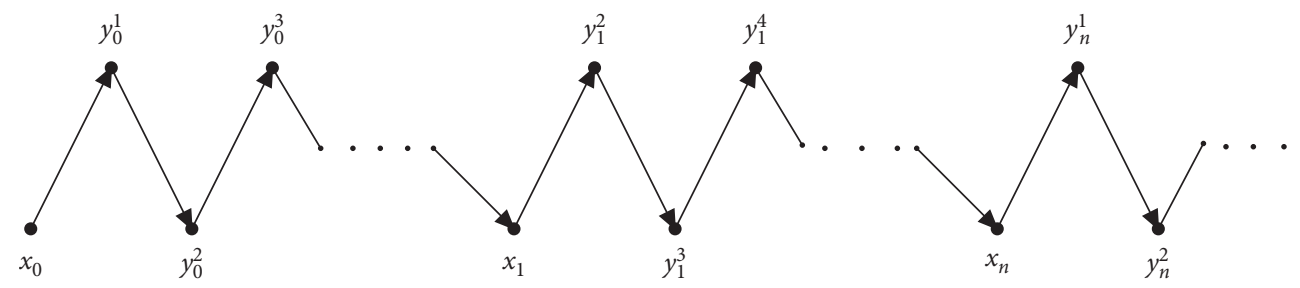

FIGURE 1: $\left(x_{n}\right)$ sequence.

(i) There exist $x_{0}$ and $x_{1}$ in $A_{0}^{p}$ such that $x_{1} \in\left[x_{0}\right]_{G} \subseteq A_{0}^{p}$ and $p\left(x_{1}-T x_{0}\right)=\operatorname{dist}_{p}(A, B)$.

(ii) For any sequence $\left(s_{n}\right)_{n}$ in $A$ with $s_{n} \longrightarrow s$ and $s_{n+1} \in\left[s_{n}\right]_{G}, s \in\left[s_{n}\right]_{G}$.

Then,

$$
\inf _{x \in A} p(x-T x)=\operatorname{dist}_{p}(A, B)
$$

Proof. $x_{0} \in A_{0}^{p}$. Let $\lambda \in[0,1)$ and define $T_{\lambda}: A \longrightarrow B$ by

$$
T_{\lambda}(x)=T\left(\lambda x_{0}+(1-\lambda) x\right) .
$$

$T_{\lambda}$ is G-contraction. By Theorem 1, there exists a best proximity point $w_{\lambda} \in A_{0}^{p}$ of $T_{\lambda}$, i.e.,

$$
p\left(w_{\lambda}-T_{\lambda}\left(w_{\lambda}\right)\right)=\operatorname{dist}_{p}(A, B) .
$$

Hence,

$$
\begin{aligned}
& p\left(\lambda x_{0}+(1-\lambda) w_{\lambda}-T\left(\lambda x_{0}+(1-\lambda) w_{\lambda}\right)\right) \\
& =p\left(\lambda x_{0}-\lambda w_{\lambda}+w_{\lambda}-T\left(\lambda x_{0}+(1-\lambda) w_{\lambda}\right)\right) \\
& \leq \lambda p\left(x_{0}-w_{\lambda}\right)+\operatorname{dist}_{p}(A, B) .
\end{aligned}
$$

Then, we have

$$
\begin{aligned}
& p\left(\lambda x_{0}+(1-\lambda) w_{\lambda}-T\left(\lambda x_{0}+(1-\lambda) w_{\lambda}\right)\right) \\
& \quad \leq \lambda \delta_{p}(A)+d i s t_{p}(A, B) .
\end{aligned}
$$

Set $x_{n}=(1 / n) x_{0}+(1-(1 / n)) w_{1 / n}$ for each $n \geq 1$. Hence by equation (31), we get

$$
p\left(x_{n}-T x_{n}\right) \leq \frac{\delta_{p}(A)}{n}+\operatorname{dist}_{p}(A, B),
$$

for all $n \geq 1$. Thus,

$$
\inf _{x \in A} p(x-T x) \leq \lim _{n \longrightarrow \infty} p\left(x_{n}-T x_{n}\right)=\operatorname{dist}_{p}(A, B) .
$$

Theorem 3. Let $(E, \mathscr{P})$ be a locally convex space endowed with a weakly convex and reflexive digraph $G$. Let $(A, B)$ be a nonempty pair with the P-property in E. Let T: $A \longrightarrow B$ be a $G$-nonexpansive mapping such that $A$ is convex complete and sequentially $[.]_{G}$-compact and $T\left(A_{0}^{p}\right) \subseteq B_{0}^{p}$. Assume that

(i) There exist $x_{0}^{0}$ and $x_{1}^{0}$ in $A_{0}^{p}$ such that $x_{1}^{0} \in\left[x_{0}^{0}\right]_{G} \subseteq A_{0}^{p}$ and $p\left(x_{1}^{0}-T x_{0}^{0}\right)=\operatorname{dist}_{p}(A, B)$.

(ii) For any sequence $\left(s_{n}\right)_{n}$ in $A$ with $s_{n} \longrightarrow s$ and $s_{n+1} \in\left[s_{n}\right]_{G}, s \in\left[s_{n}\right]_{G}$.
Then, $T$ has a best proximity point $x$ in the sense that

$$
p(x-T x)=\operatorname{dist}_{p}(A, B) .
$$

Proof. Let $p \in \mathscr{P}$ and $\lambda_{1} \in(0,1)$. Set

$$
T_{1}(x)=T\left(\lambda_{1} x_{0}^{0}+\left(1-\lambda_{1}\right) x\right) .
$$

Since $A_{0}^{p}$ is convex and $T\left(A_{0}^{p}\right) \subseteq B_{0}^{p}$, we get $T_{1}\left(A_{0}^{p}\right) \subseteq B_{0}^{p}$, and since $T_{1}\left(x_{0}^{0}\right)=T\left(x_{0}^{0}\right)$, there exists $x_{0}^{1} \in A_{0}^{p}$ such that

$$
\begin{gathered}
x_{0}^{1} \in\left[x_{0}^{0}\right]_{G}, \\
p\left(x_{0}^{1}-T_{1}\left(x_{0}^{0}\right)\right)=\operatorname{dist}_{p}(A, B) .
\end{gathered}
$$

As $T_{1}$ is $G$-contraction, by Theorem $1, T_{1}$ has a best point proximity $x_{1}^{*}$ such that

$$
x_{1}^{*} \in\left[x_{0}^{0}\right]_{G} .
$$

Again, let $\lambda_{2} \in(0,1) \quad$ with $\quad \lambda_{1}<\lambda_{2}$. Set $T_{2}(x)=T\left(\lambda_{2} x_{1}^{*}+\left(1-\lambda_{2}\right) x\right)$. We have

$$
T_{2}\left(x_{1}^{*}\right)=T\left(x_{1}^{*}\right) \in B_{0}^{p} .
$$

So, there exists $x_{1}^{1} \in A_{0}^{p}$ such that

$$
p\left(x_{1}^{1}-T_{2}\left(x_{1}^{*}\right)\right)=\operatorname{dist}_{p}(A, B)
$$

and by the above construction, we also have $p\left(x_{1}^{1}-T_{2}\left(x_{1}^{*}\right)\right)=p\left(x_{1}^{*}-T_{1}\left(x_{1}^{*}\right)\right)$. That is,

$$
\left\{\begin{array}{l}
p\left(x_{1}^{1}-T\left(\lambda_{1} x_{1}^{*}+\left(1-\lambda_{1}\right) x_{1}^{*}\right)\right)=\operatorname{dist}_{p}(A, B), \\
p\left(x_{1}^{*}-T\left(\lambda_{1} x_{0}^{0}+\left(1-\lambda_{1}\right) x_{1}^{*}\right)\right)=\operatorname{dist}_{p}(A, B) .
\end{array}\right.
$$

Since $T$ is $G$-nonexpansive and $G$ is weakly reflexive convex graph, we obtain

$$
\begin{gathered}
x_{1}^{1} \in\left[x_{1}^{*}\right]_{G}, \\
p\left(x_{1}^{1}-T_{2}\left(x_{1}^{*}\right)\right)=\operatorname{dist}_{p}(A, B),
\end{gathered}
$$

and as $T_{2}$ is $G$-contraction, then $T_{2}$ has a best proximity point $x_{2}^{*} \in A_{0}^{p}$ that satisfies

$$
x_{2}^{*} \in\left[x_{1}^{1}\right]_{G} \text {. }
$$

Continuing in this manner we construct a sequence of mappings $\left(T_{n}\right)$ satisfying for all $n \geq 0$ :

$$
\left\{\begin{array}{l}
T_{n+1}(x)=T\left(\lambda_{n+1} x_{n}^{*}+\left(1-\lambda_{n+1}\right) x\right), \\
x_{n+1}^{*} \in\left[x_{n}^{*}\right]_{G} \\
x_{0}^{*}=x_{0}^{0}
\end{array}\right.
$$


where $\left(\lambda_{n}\right)$ is a nondecreasing sequence of $(0,1)$.

Note that $T_{n+1}$ is a $G$-contraction with $x_{n+1}^{*}$ as its best proximity point. Since $x_{n+1}^{*} \in\left[x_{n}^{*}\right]_{G}$ for any $n \in \mathbb{N}$ and $A$ is $[.]_{G}$-compact, there exists a subsequence $\left(x_{n_{k}}^{*}\right)_{k}$ witch converges to $x^{*}$ in $A$ and satisfies

$$
x^{*} \in\left[x_{n_{k}}^{*}\right]_{G},
$$

for any $k . T$ is $G$-nonexpansive mapping; thus,

$$
p\left(T x_{n_{k}}^{*}-T x^{*}\right) \leq p\left(x_{n_{k}}^{*}-x^{*}\right) \longrightarrow 0,
$$

i.e.,

$$
T x_{n_{k}}^{*} \longrightarrow T x^{*} .
$$

The above yields to

$$
\begin{aligned}
p\left(x^{*}-T x^{*}\right) \leq & p\left(x^{*}-x_{n_{k+1}}^{*}\right)+p\left(x_{n_{k+1}}^{*}-T_{n_{k+1}}\left(x_{n_{k+1}}^{*}\right)\right) \\
& +p\left(T_{n_{k+1}}\left(x_{n_{k+1}}^{*}\right)-T_{n_{k+1}}\left(x_{n_{k}}^{*}\right)\right) \\
& +p\left(T x_{n_{k}}^{*}-T x^{*}\right) \leq p\left(x^{*}-x_{n_{k+1}}^{*}\right) \\
& +p\left(x_{n_{k+1}}^{*}-T_{n_{k+1}}\left(x_{n_{k+1}}^{*}\right)\right) \\
& +\left(1-\lambda_{n_{k+1}}\right) p\left(x_{n_{k+1}}^{*}-x_{n_{k}}^{*}\right)+p\left(T x_{n_{k}}^{*}-T x^{*}\right),
\end{aligned}
$$

and since

$$
p\left(x_{n_{k+1}^{*}}-T_{n_{k+1}}\left(x_{n_{k+1}}^{*}\right)\right)=\operatorname{dist}_{p}(A, B)
$$

for any $k \in \mathbb{N}$, we get

$$
p\left(x^{*}-T x^{*}\right)=\operatorname{dist}_{p}(A, B) .
$$

Example 1. Let $X$ be the space of continuous real functions, i.e.,

$$
X=C(\mathbb{R})=\{f: \mathbb{R} \longrightarrow \mathbb{R}: \text { continuous }\}
$$

Let $\mathscr{P}=\left\{p_{K}\right\}_{K \subset \mathbb{R}}$ be the family of seminorms generated the topology of $X$ such that for every $f \in X$ and $K$, a compact of $\mathbb{R}$, we have

$$
p_{K}(f)=\max _{x \in K}|f(x)| \text {. }
$$

Let

$$
\begin{aligned}
& A=\left\{\lambda\left(1-\frac{1}{n}\right)+(1-\lambda)\left(1-\frac{1}{m}\right): \lambda \in[0,1] \text { and } m, n \in \mathbb{N}^{*}\right\} \cup\{1\}, \\
& B=\left\{\lambda\left(2+\frac{1}{n}\right)+(1-\lambda)\left(2+\frac{1}{m}\right): \lambda \in[0,1] \text { and } m, n \in \mathbb{N}^{*}\right\} \cup\{2\}
\end{aligned}
$$

Then, $A$ is convex. Moreover, we have

$$
p_{K}(1-2)=1=\operatorname{dist}_{p_{K}}(A, B) \text {. }
$$

Thus,

$$
A_{0}^{p_{K}}=\{1\}
$$

So, $(A, B)$ has the $P$-property.

Let $f_{1}, f_{2} \in A$. We define a digraph $G$ on $A$ as follows:

$$
\left(f_{1}, f_{2}\right) \in E(G) \Leftrightarrow \exists c \in[1,2] \text { such that } f_{1} \leq c f_{2} \text {. }
$$

Then, $G$ is weakly convex and reflexive digraph. Obviously, $A$ is sequentially $[.]_{G}$-compact. Since
$p_{K}(1-T 1)=\operatorname{dist}_{p_{K}}(A, B)$, assumption (i) of Theorem 3 holds.

Now, let $T: A \longrightarrow B$ be the mapping defined by

$$
\begin{aligned}
& T\left(\lambda\left(1-\frac{1}{n}\right)+(1-\lambda)\left(1-\frac{1}{m}\right)\right)=\lambda\left(2+\frac{1}{n}\right) \\
& \quad+(1-\lambda)\left(2+\frac{1}{m}\right)
\end{aligned}
$$$$
T(1)=2 \text {. }
$$

$T$ is $G$-nonexpansive since we have

$$
\begin{aligned}
p_{K} & {\left[T\left(\lambda\left(1-\frac{1}{n}\right)+(1-\lambda) 1-\frac{1}{m}\right)-T\left(\lambda^{\prime}\left(1-\frac{1}{n^{\prime}}\right)+\left(1-\lambda^{\prime}\right)\left(1-\frac{1}{m^{\prime}}\right)\right)\right] } \\
& =p_{K}\left[\lambda\left(2+\frac{1}{n}\right)+(1-\lambda)\left(2+\frac{1}{m}\right)-\lambda^{\prime}\left(2+\frac{1}{n^{\prime}}\right)-\left(1-\lambda^{\prime}\right)\left(2+\frac{1}{m^{\prime}}\right)\right] \\
& =p_{K}\left[\lambda\left(1-\frac{1}{n}\right)+(1-\lambda)\left(1-\frac{1}{m}\right)-\lambda^{\prime}\left(1-\frac{1}{n^{\prime}}\right)-\left(1-\lambda^{\prime}\right)\left(1-\frac{1}{m^{\prime}}\right)\right] .
\end{aligned}
$$


So, $T$ is $G$-nonexpansive and $T\left(A_{0}^{p_{K}}\right) \subseteq B_{0}^{p_{K}}$. Then, there exists $f \in A$ such that

$$
p_{K}(f-T f)=\operatorname{dist}_{p_{K}}(A, B) .
$$

Indeed the only such point is $f$ such that $f(x)=$ 1 for any $x \in \mathbb{R}$.

If the digraph $G$ is partial order, we get the following interesting consequence.

Corollary 1. Let $(E, \mathscr{P})$ be a locally convex space endowed with a partial order $\prec$. Let $(A, B)$ be a nonempty pair with the P-property in $E$. Let $T: A \longrightarrow B$ be a $<$-nonexpansive mapping such that $A$ is convex complete and sequentially $\prec$-compact and $T\left(A_{0}^{p}\right) \subseteq B_{0}^{p}$. Assume that

(i) There exist $x_{0}^{0}$ and $x_{1}^{0}$ in $A_{0}^{p}$ such that $x_{1}^{0} \leq x_{0}^{0}$ and $p\left(x_{1}^{0}-T x_{0}^{0}\right)=\operatorname{dist}_{p}(A, B)$.

(ii) For any sequence $\left(s_{n}\right)_{n}$ in $A$ with $s_{n} \longrightarrow s$ and $s_{n+1} \prec s_{n}$, we have $s<s_{n}$.

Then, $T$ has a best proximity point $x$ in the sense that

$$
p(x-T x)=\operatorname{dist}_{p}(A, B) .
$$

Example 3.6. Let $X$ be the space of real sequences, i.e.,

$$
X=\mathbb{R}^{\mathbb{N}}=\left\{x=\left(x_{i}\right)_{i \in \mathbb{N}}: x_{i} \in \mathbb{R}\right\} .
$$

Let $\mathscr{P}=\left\{p_{n}\right\}_{n \in \mathbb{N}}$ be the family of seminorms generated the topology of $X$ such that for every $x=\left(x_{i}\right)_{i \geq 1} \in X$,

$$
p_{n}(x)=\max _{1 \leq i \leq n}\left|x_{i}\right| .
$$

Suppose that $\left\{e_{k}\right\}_{k \in \mathbb{N}}$ is the canonical basis of $X$ and let

$$
\begin{aligned}
& A=\left\{\lambda e_{1}+(1-\lambda) e_{2}: \lambda \in[0,1]\right\}, \\
& B=\left\{\lambda e_{3}+(1-\lambda) e_{4}: \lambda \in[0,1]\right\} .
\end{aligned}
$$

Then, $A$ is weakly compact subset of $X$ since it is convex bounded and closed. Moreover, as for each $\lambda \in[0,1]$, we have $(1 / 2) \leq \max (\lambda ; 1-\lambda)$; thus, for all $n \in \mathbb{N}$, we have

$$
p_{n}\left(\frac{e_{1}+e_{2}}{2}-\frac{e_{3}+e_{4}}{2}\right)=\frac{1}{2}=\operatorname{dist}_{p_{n}}(A, B) .
$$

Thus,

$$
A_{0}^{p_{n}}=\left\{\frac{e_{1}+e_{2}}{2}\right\} .
$$

So, $(A, B)$ has $P$-property.

Let $x_{1}, x_{2} \in A$. We define a partial order on $A$ as follows:

$$
x_{1} \prec x_{2} \Leftrightarrow \lambda_{1} \leq \lambda_{2},
$$

where $x_{i}=\lambda_{i} e_{1}+\left(1-\lambda_{i}\right) e_{2}$ for $i=1,2$.

$A$ is obviously sequentially $\prec$-compact.

Now, let $T: A \longrightarrow B$ be the mapping defined by

$$
T\left(\lambda e_{1}+(1-\lambda) e_{2}\right)=\lambda e_{3}+(1-\lambda) e_{4},
$$

for each $\lambda \in[0,1] . T$ is $\prec$-nonexpansive since for every $i \in \mathbb{N}$, we have

$$
\begin{aligned}
p_{n} & {\left[T\left(\lambda_{i} e_{1}+\left(1-\lambda_{i}\right) e_{2}\right)-T\left(\lambda_{i+1} e_{1}+\left(1-\lambda_{i+1}\right) e_{2}\right)\right] } \\
& =p_{n}\left[\lambda_{i} e_{3}+\left(1-\lambda_{i}\right) e_{4}-\lambda_{i+1} e_{3}+\left(1-\lambda_{i+1}\right) e_{4}\right] \\
& =p_{n}\left[\lambda_{i} e_{1}+\left(1-\lambda_{i}\right) e_{2}-\lambda_{i+1} e_{1}+\left(1-\lambda_{i+1}\right) e_{2}\right] .
\end{aligned}
$$

So, $T$ is $\prec$-nonexpansive and $T\left(A_{0}^{p}\right) \subseteq B_{0}^{p}=\left\{\left(e_{3}+e_{4}\right) / 2\right\}$. Then, there exists $x \in A$ such that

$$
p_{n}(x-T x)=\operatorname{dist}_{p_{n}}(A, B) .
$$

Indeed the only such point is $x=\left(\left(e_{1}+e_{2}\right) / 2\right)$.

In order to get a common best proximity point with respect to every seminorm $p_{\alpha}$, we have the next result.

Theorem 4. Let $\left(E, \mathscr{P}=\left(p_{\alpha}\right)_{\alpha \in \Omega}\right)$ be a locally convex space endowed with a digraph $G$ which is weakly convex and reflexive. Let $(A, B)$ be a nonempty pair with the P-property in E. Let $T: A \longrightarrow B$ be a G-nonexpansive mapping such that $A$ is convex complete and $[.]_{G}$-compact and $T\left(A_{0}^{p_{\alpha}}\right) \subseteq B_{0}^{p_{\alpha}}$. Assume that

(i) There exist $x_{0}$ and $x_{1}$ in $A_{0}^{p_{\alpha}}$ such that $x_{1} \in\left[x_{0}\right]_{G} \subseteq A_{0}^{p_{\alpha}}$ and $p_{\alpha}\left(x_{1}-T x_{0}\right)=\operatorname{dist}_{p_{\alpha}}(A, B)$ for all $\alpha \in \Omega$.

(ii) For any two elements $x, y$ in $A$, there is a finite path between them.

(iii) For any net $\left(s_{\alpha}\right)_{\alpha \in \Omega}$ in $A$ with $s_{\alpha} \longrightarrow s$ and $s_{\alpha} \in\left[s_{\beta}\right]_{G} \forall \beta<\alpha$, we have $\in\left[s_{\alpha}\right]_{G} \forall \alpha \in \Omega$.

Then, $T$ has a best proximity point in the sense that there is $x^{*} \in A$ such that

$$
p\left(x^{*}-T x^{*}\right)=\operatorname{dist}_{p}(A, B) \text { for any } p \in \mathscr{P} .
$$

Proof. Let $\alpha \in \Omega$. By Theorem 3, there exist $x_{\alpha} \in A_{0}^{p_{\alpha}}$ such that

$$
p_{\alpha}\left(x_{\alpha}-T x_{\alpha}\right)=\operatorname{dist}_{p_{\alpha}}(A, B) .
$$

Applying (ii) and the fact that $A$ is $[.]_{G^{-}}$-compact, the net $\left(x_{\alpha}\right)_{\alpha \in \Omega}$ has a converging subnet $\left(x_{\alpha}\right)_{\alpha^{\prime} \in \Omega^{\prime}}$ which is converging to $x^{*}$ with $x^{*} \in\left[x_{\alpha^{\prime}}\right]_{G}$ for any $\alpha^{\prime} \in \Omega^{\prime}$. Moreover, we have for all $\alpha^{\prime} \in \Omega^{\prime}$,

$$
\begin{aligned}
p_{\alpha^{\prime}}\left(x^{*}-T x^{*}\right) \leq & p_{\alpha^{\prime}}\left(x^{*}-x_{\alpha^{\prime}}\right)+p_{\alpha^{\prime}}\left(x_{\alpha^{\prime}}-T x_{\alpha^{\prime}}\right) \\
& +p_{\alpha^{\prime}}\left(T x_{\alpha^{\prime}}-T x^{*}\right) \leq p_{\alpha^{\prime}}\left(x^{*}-x_{\alpha^{\prime}}\right) \\
& +p_{\alpha^{\prime}}\left(x_{\alpha^{\prime}}-T x_{\alpha^{\prime}}\right) \\
& +p\left(x_{\alpha^{\prime}}-x^{*}\right) \leq 2 p\left(x^{*}-x_{\alpha^{\prime}}\right) \\
& +p\left(x_{\alpha^{\prime}}-T x_{\alpha_{\prime}}\right)=2 p\left(x^{*}-x_{\alpha^{\prime}}\right) \\
& +\operatorname{dist}_{\alpha^{\prime}}(A, B) \leq \varepsilon+\operatorname{dist}_{\alpha^{\prime}}(A, B),
\end{aligned}
$$

for all $\varepsilon>0$. The proof is completed.

\section{Data Availability}

No data were used to support this study. 


\section{Conflicts of Interest}

The authors declare that there are no conflicts of interest regarding the publication of this paper.

\section{References}

[1] H. Aydi, H. Lakzian, Z. D. Mitrović, and S. Radenović, "Best proximity points of $\mathrm{mt}$-cyclic contractions with property UC," Numerical Functional Analysis and Optimization, vol. 41, no. 7, pp. 871-882, 2020.

[2] K. Chaira and S. Lazaiz, "Best proximity point theorems for cyclic relatively-nonexpansive mappings in modular spaces," Abstract and Applied Analysis, vol. 2018, Article ID 8084712, 8 pages, 2018.

[3] A. A. Eldred, W. A. Kirk, and P. Veeramani, "Proximal normal structure and relatively nonexpansive mappings," Studia Mathematica, vol. 171, pp. 283-293, 2005.

[4] M. Gabeleh, "Cyclic relatively nonexpansive mappings in convex metric spaces," Miskolc Mathematical Notes, vol. 16, no. 1, pp. 133-144, 2015.

[5] S. Sahmim, A. Felhi, and H. Aydi, "Convergence and best proximity points for generalized contraction pairs," Mathematics, vol. 7, no. 2, p. 176, 2019.

[6] V. Sankar R. and P. Veeramani, "Best proximity pair theorems for relatively nonexpansive mappings," Applied General Topology, vol. 10, no. 1, pp. 21-28, 2009.

[7] K. Fan, "Fixed-point and minimax theorems in locally convex topological linear spaces," Proceedings of the National Academy of Sciences, vol. 38, no. 2, pp. 121-126, 1952.

[8] J. M. Ling, "Fixed points of nonexpansive maps on locally convex spaces," Bulletin of the Korean Mathematical Society, vol. 37 , no. 1 , pp. 21-36, 2000.

[9] A. T.-M. Lau and W. Takahashi, "Invariant submeans and semigroups of nonexpansive mappings on banach spaces with normal structure," Journal of Functional Analysis, vol. 142, no. 1, pp. 79-88, 1996.

[10] H. D. Vuong, "A fixed point theorem for nonexpansive mappings in locally convex spaces," Vietnam Journal of Mathematics, vol. 34, 2006.

[11] M. Rigo, Advanced Graph Theory and Combinatorics, John Wiley \& Sons, Hoboken, NJ, USA, 2016.

[12] A. Sultana and V. Vetrivel, "Best proximity points of contractive mappings on a metric space with a graph and applications," Applied General Topology, vol. 18, no. 1, pp. 13-21, 2017. 